\title{
O salutarismo de Robert Crawford e as atualizações do autoritarismo sanitário nosso de cada dia
}

\author{
The healthism by Robert Crawford and the sanitary authoritarianism \\ update in our daily life
}

\section{El healthism según Robert Crawford y las actualizaciones del nuestro autoritarismo sanitario de cada día}

\author{
Danielle Ribeiro de Moraes ${ }^{1, a}$ \\ arq.drm@gmail.com | https://orcid.org/0000-0002-5600-5412 \\ Luis David Castiel ${ }^{1, a}$ \\ luis.castiel@ensp.fiocruz.br| https://orcid.org/0000-0001-9528-8075 \\ ${ }^{1}$ Fundação Oswaldo Cruz, Escola Nacional de Saúde Pública Sergio Arouca. Rio de Janeiro, RJ, Brasil. \\ a Doutorado em Saúde Pública pela Fundação Oswaldo Cruz.
}

\section{Resumo}

Neste ensaio, exploramos possibilidades de uso do conceito de salutarismo (healthism), conforme abordado por Robert Crawford em 1980. Enfatizamos a dimensão individualizante explorada no desenvolvimento deste conceito e a situamos como um aspecto central no discurso médico, que opera na base das ações relacionadas à ideia dominante sobre promoção da saúde. Esta centralidade ocupa um lugar estratégico na atualidade, na medida em que enseja práticas de uma moralidade sanitária despolitizadora e autoritária, condizentes com a racionalidade neoliberal.

Palavras-chave: Salutarismo; Saúde pública; Neoliberalismo; Promoção da saúde; Discurso médico.

\begin{abstract}
In this essay, we explore possibilities of using the concept of healthism, as discussed by Robert Crawford in 1980. We emphasize the individualized dimension exposed in the development of this concept, presenting it as a central aspect in medical discourse, which operates on the basis of dominant idea of health promotion and its related actions. This centrality occupies a strategic place in the present time, inasmuch as it impels depoliticized and authoritarian practices and a sanitary morality, consistent with neoliberal rationality.
\end{abstract}

Keywords: Healthism; Public health; Neoliberalism; Health promotion; Medical discourse. 


\section{Resumen}

En este ensayo, exploramos posibilidades de uso del concepto de healthism, según lo abordado por Robert Crawford en 1980. Enfatizamos la dimensión individualizante explotada en el desarrollo de este concepto y la situamos como un aspecto central en el discurso médico, que opera en la base de las acciones relacionadas con la idea dominante de la promoción de la salud. Esta centralidad ocupa un lugar estratégico en la actualidad, puesto que incita a prácticas y a una moralidad sanitaria despolitizadora y autoritaria, consonantes con la racionalidad neoliberal.

Palabras clave: Healthism; Salud pública; Neoliberalismo; Promoción de la salud; Discurso médico.

Contribuição dos autores: ambos os autores são responsáveis por todo o texto.

Declaração de conflito de interesses: não há.

Fontes de financiamento: não houve.

Considerações éticas: não há.

Agradecimentos/Contribuições adicionais: não há.

Histórico do artigo: submetido: 08.fev.2019 | aceito: 20.fev.2019 | publicado: 29.mar.2019.

Apresentação anterior: não houve.

Licença CC BY-NC atribuição não comercial. Com essa licença é permitido acessar, baixar (download), copiar, imprimir, compartilhar, reutilizar e distribuir os artigos, desde que para uso não comercial e com a citação da fonte, conferindo os devidos créditos de autoria e menção à Reciis. Nesses casos, nenhuma permissão é necessária por parte dos autores ou dos editores. 


\section{Salutarismo e o lugar da hipervalorização da saúde}

O artigo 'Salutarismo e medicalização da vida cotidiana', em 2019, faz 39 anos de publicação. Numa iniciativa importante e muito oportuna, a Revista Eletrônica de Comunicação, Informação e Inovação em Saúde (Reciis) verte-o para a língua portuguesa ${ }^{1}$. Antes de mais nada, essa é uma leitura fundamental para quem se envereda pela abordagem crítica do campo da saúde pública (e/ou da saúde coletiva). Isto porque o artigo de Robert Crawford diz muito da dinâmica de configuração do campo da saúde de nossos dias.

Crawford é um cientista político estadunidense, que obteve seu $\mathrm{PhD}$ em 1974. É professor emérito da Escola de Ciências e Artes Interdisciplinares, na Universidade de Washington em Tacoma, EUA. Como parte de sua militância, atualmente apresenta-se como ativista dos Direitos Humanos, sendo membro do Centro de Direitos Humanos daquela universidade. Entre os itens de seu currículo, destacam-se não apenas os ensaios sobre os movimentos da saúde, mas também cursos sobre o racismo, holocausto e os direitos civis. Chamam a atenção as resenhas que seus colegas fazem sobre sua vida acadêmica, identificando-o como 'um eterno professor', o que sinaliza a tomada de posição política e o engajamento acadêmico que o autor sustenta ${ }^{2,3}$.

$\mathrm{O}$ artigo em tela foi originalmente publicado no periódico International Journal of Health Services (IJHS), que, pelo menos entre as décadas de 1970 e 1990, foi um espaço ocupado por vários textos ancorados na abordagem crítica às repercussões do neoliberalismo sobre o setor e o campo da saúde, sobretudo pela existência de uma seção destinada a discussões sobre epistemologia e políticas de saúde. Podemos identificar vários dos textos daquela revista povoando trabalhos que contribuíram para embasar a constituição do campo da saúde coletiva, no Brasil. Muitos deles ainda são utilizados como bibliografia em cursos de pós-graduação da área. Entre eles, destacamos os de Deborah Lupton ${ }^{4}$, Evan Stark ${ }^{5}$ e do próprio Robert Crawford ${ }^{6,7}$.

De acesso restrito à pagantes, a empresa transnacional Sage Publishing atualmente detém a permissão sobre a comercialização da IJH'. A exemplo de outras empresas similares, a Sage não é apenas uma 'editora' que se põe a selecionar e publicar. Ela atua no ramo de produção de conteúdo acadêmico e tem como produtos: periódicos científicos, livros, arquivos, bancos de dados e vídeos. É responsável pela venda do acesso a mais de mil periódicos científicos e pela publicação de cerca de 800 novos livros por ano. Atualmente possui escritórios nos Estados Unidos, Reino Unido, Índia, Singapura e Austrália9.

Observar a contradição da existência de textos de cunho crítico em periódicos, cujo acesso é um produto a ser vendido por empresas transnacionais. já nos depara com um cenário de enunciados paradoxais com os quais temos de lidar atualmente ${ }^{10}$. Mas, como apontado no ensaio, o salutarismo é em si mais um aparente paradoxo da atualidade. O neologismo utilizado por Crawford foi inicialmente mencionado em um ensaio de Irving Zola chamado Healthism and Disabling Medicalization ${ }^{11}$, de 1977. O livro Disabling Professions, no qual foi publicado o ensaio de Zola, tem como organizador um grupo de colaboradores de Ivan Illich, cuja obra Nemesis Medica ${ }^{12}$ teve notável propagação, sendo traduzida para vários idiomas.

Ainda que Crawford vá apresentar uma crítica que se afasta em alguma medida da ideia de medicalização defendida por Illich e Zola, é importante notar que o uso do termo healthism surge como uma crítica ao próprio 'espírito da época' em que essas mensagens contraditórias nos são insistentemente apresentadas. Como será comentado, essa mistura de distintas orientações de conduta é uma marca ainda atual do discurso médico, que permeia a produção acadêmica e as práticas sanitárias até hoje ${ }^{13}$. Podemos dizer que um padrão de ressonância sanitária moralizante ecoa na produção das subjetividades atuais, produzindo e sendo reproduzido pela ideologia ou racionalidade neoliberal ${ }^{14,15}$. E Crawford é um autor que já descrevia as condições que possibilitaram esta situação.

\footnotetext{
i Segundo o Catálogo Coletivo Nacional de Publicações Seriadas ${ }^{8}$, dezesseis bibliotecas brasileiras detêm exemplares físicos deste periódico. O Instituto de Comunicação e Informação Científica e Tecnológica em Saúde (Icict), da Fundação Oswaldo Cruz, é a instituição que dispõe do maior número de volumes e números da revista.
} 
Com uma visão arguta sobre os movimentos sociais e da saúde que aconteciam nos Estados Unidos da América (EUA) no final da década de 1970, o autor localiza que lugar ocupa a (hiper)valorização da obtenção e manutenção da saúde em tempos de transformações do capital industrial, das relações de trabalho, e do fortalecimento do capital financeiro. E é com a perspectiva dessas transformações em mente que se deve localizar a constituição do campo da saúde coletiva, seu discurso e as ainda atuais prescrições de conduta.

Robert Crawford apresenta no ensaio ora traduzido suas percepções sobre os modos de se apresentar a ideia de salutarismo nos EUA. Com base em seu trabalho de pesquisa, muito dela de cunho etnográfico dos anos anteriores à publicação, defende, como centralidade de seus argumentos, a consolidação de um deslocamento: se com a modernidade a manutenção da saúde passou a ser de ordem pública, no momento do desenvolvimento de seu ensaio, é a "privatização do esforço para o bem-estar geral"1 que toma corpo. $\mathrm{O}$ autor sinaliza que isso ocorre nos movimentos de saúde, que assumem o que nomeia de uma nova "consciência de saúde", marcada pelo fundamento ideológico da medicalização da vida.

Nesse texto, ele se debruça sobre tendências como as de autocuidado e de saúde holística, que ganhavam força e se espraiavam entre a população dos EUA. Apresenta de modo detalhado as características desses movimentos que tanto transformam a questão pública de saúde para a esfera individual, quanto residiriam na volição - e na capacidade de fazer escolhas consideradas "mais saudáveis"1 - dos indivíduos.

O terreno para esse deslocamento foi pavimentado pela emergência da "ideologia de culpabilização da vítima”, exposta em um artigo anterior ${ }^{6}$. Em outras palavras, se no artigo sobre salutarismo Crawford expõe como a tendência individualizadora deposita a esperança do bem-estar sanitário nas pessoas, no texto de 1977 ele apresenta as condições para que essa individualização ocorresse: sendo tributária não só dos processos de reestruturação produtiva, com a flexibilização e a precarização do trabalho correndo lado a lado do enfraquecimento dos movimentos de trabalhadores; como também da pauta de ampliação do acesso à saúde que emergia no período, ainda que diante das reformas de Estado que aconteceram nos países centrais na década de 1980.

De modo bastante esquemático, o que caracteriza o aspecto culpabilizador é a conclusão quase automática que, se o indivíduo escolhe não se prevenir, apesar de ser devidamente informado das formas eficazes de evitar doenças, deveria recair sobre ele a responsabilidade de arcar com os custos (pecuniários ou não) de seu adoecimento. Assim, comportamentos foram sendo tachados de "não saudáveis" e, portanto, moralmente execráveis à luz do discurso do risco, em que se baseia a promoção da saúde .

De modo geral, não se colocam em questão os motivos que levam a esses comportamentos, sejam eles ligados à cultura local, a contextos sociais desfavoráveis, à hiperexploração de trabalhadores ou à ordem macroeconômica, que atualmente deu à concentração de renda ares hiperbólicos. Os scripts preventivos, por estarem calçados na 'melhor cientificidade' epidemiológica, são tidos como universais e, portanto, devem ser adotados universalmente. Eis uma falácia que povoa e vem constituindo os campos da saúde e da saúde coletiva ${ }^{13}$.

Nesse sentido, o fortalecimento do discurso da promoção da saúde serviu de modo estratégico à frenagem da pauta dos serviços de saúde que oferecessem o que, no Brasil, chamamos de integralidade das ações. Esse discurso tem uma dupla marca. Em primeiro lugar, apesar de manter enunciada a ideia de participação social no campo da saúde, ele coloca como centrais as mudanças de hábitos e a categoria 'estilo de vida', ambas voltadas para a prevenção de doenças. Essas ideias-força do campo foram fortalecidas pela epidemiologia dos fatores de risco ${ }^{16}$, que funcionou como marco explicativo mais difundido das mudanças na distribuição da morbimortalidade: da predominância de doenças infecciosas para a das doenças e agravos não transmissíveis, como as doenças cardiovasculares. Esse processo foi inicialmente chamado de transição epidemiológica, uma vez que se cria algo como um estágio pelo qual os países iriam passar em seu processo de desenvolvimento ${ }^{17}$.

Posteriormente, com a epidemia de HIV/Aids e a permanência das chamadas doenças negligenciadas, críticas a essa visão apareceram, indicando a importância de trazer para a análise os elementos da 
determinação histórica e social dos processos de adoecimento ${ }^{18,19}$. Do ponto de vista da constituição do campo da saúde coletiva, são especialmente importantes os aportes da medicina social latino-americana ${ }^{20}$. No entanto, ainda que diante dessas leituras críticas do campo e de desenhos de políticas de saúde aparentemente mais progressistas, o marco explicativo inicial ainda permanece como dominante na produção do discurso médico e da promoção da saúde, servindo como exemplo a revisão de Silva, Cotta e Rosa ${ }^{21}$. Esta predominância pode ser verificada em diferentes loci de enunciação, tais como os textos acadêmicos de periódicos de maior circulação e expressão na formação de opinião médica, as campanhas oficiais de comunicação em saúde e as diferentes formas de midiatização do campo ${ }^{22,23}$.

Em segundo lugar, é importante sinalizar que a promoção da saúde pode ser compreendida em si como uma forma de medicalização. Essas ondas salutaristas mais 'naturais' poderiam, aparentemente, compor um repertório mais independente dos processos de medicalização institucional, uma vez que a antimedicina foi bastante difundida e esses próprios movimentos se utilizavam desse argumento ${ }^{12}$. Afinal, tratava-se de questionar, na época, o potencial iatrogênico de práticas que tinham como efeitos aparentes a superutilização dos serviços de saúde, com seus procedimentos e condutas clínicas fragmentadas na hiperespecialização. Essas críticas achavam eco, também, no medo liberal de propostas de sistemas e práticas estatizados de saúde na conjuntura da Guerra Fria, sob a sombra da corrida armamentista.

O autocuidado e a perspectiva holística, nesse contexto, representavam o desejo de independência desse circuito. Porém, tais práticas se encaixavam, e ainda se encaixam, na promoção da saúde, se tomarmos o discurso hegemônico neste campo. Para autores com abordagens mais críticas, entre os quais destacamos alguns ${ }^{24-31}$, a promoção da saúde, como corolário e sob o signo da prevenção, serve a ampliar o escopo da normatização do corpo e da vida para além daqueles que estão doentes, seja pela amplitude das práticas preconizadas, seja por sua dimensão pedagógica.

Afinal, quando saúde se torna um supervalor, meios que a princípio veríamos como apartados, como a realização de exercícios físicos, o (auto)cuidado com a alimentação, e até propostas anteriormente chamadas de medicinas alternativas, passam a fazer parte do mesmo complexo produtivo de circulação de capital das internações e do hiperuso dos sistemas de saúde. Isso se entendermos medicalização como a circunscrição da vida à matriz explicativa e às práticas sanitárias, dada a hegemonia de seu caráter regulatório, aos moldes da crítica de Michel Foucault ${ }^{32}$.

Conforme vemos no ensaio traduzido, Crawford analisa mudanças nos padrões de consumo dadas pela valorização da temática saúde, calcada em uma retórica e na cultura distintiva da classe média, sobretudo a estadunidense. Essa valorização se distingue das pautas de luta da classe trabalhadora por melhores condições de trabalho que, ainda que focadas na saúde, tinham como pontos fulcrais a chamada "saúde ocupacional" e a segurança no trabalho. $\mathrm{O}$ que ganhou espaço foram enunciados essencialmente centrados na busca e na conquista da saúde individual, cuja obtenção e manejo ficam por conta da vontade e da força dos indivíduos.

É a partir dessa constatação que o autor caminha em seu ensaio sobre o salutarismo e por suas dimensões de práticas sociais, que se tornam desejáveis, uma vez que se encaixam no script sanitário que se apresenta ao longo das décadas seguintes. Como o próprio Crawford já sinalizava no texto de 1980 e retoma na primeira década do século $\mathrm{XXI}^{33}$, há de se entender saúde como uma questão produtora de sentidos na contemporaneidade. Para ele, "numa cultura de valorização da saúde, as pessoas definem a si mesmas em parte pelo quanto são bem-sucedidas ao adotarem práticas saudáveis e pelas qualidades de caráter ou personalidade que acreditam sustentar comportamentos saudáveis. Elas avaliam os outros pelos mesmos critérios" 33 . Este seria um efeito da expansão dos fenômenos sociais relacionados à saúde, necessariamente ligados à biomedicina e ao mercado sanitário, que amplia suas fronteiras. Para o autor, que analisa no texto de 2006 a sociedade estadunidense, isso se constituiu em um modelo para a (re) construção do neoliberalismo. 


\section{O que faz com que as observações de Crawford façam tanto sentido nos dias atuais?}

Como se pode perceber, discutir o ensaio de Crawford, publicado originalmente em 1980, utilizando tanto seus trabalhos mais recentes sobre o campo da saúde, quanto textos contemporâneos de outros autores, parece-nos bastante cabível. Acreditamos que não se trata de um anacronismo, já que a ideia de saúde como supervalor, apresentada originalmente pelo autor, mostra-se constantemente atualizada.

Se fizermos buscas na base de recuperação de referências Scopus, da empresa transnacional Elsevier, que congrega milhares de periódicos de diversas áreas, veremos que a discussão sobre salutarismo continua a ser tematizada. Como exemplo, ao buscar apenas a expressão em inglês para salutarismo - healthism - e limitarmos a busca à palavras-chave, título e resumo, recuperam-se 159 documentos ${ }^{\mathrm{ii}}$. Acreditamos que seja uma cifra expressiva, considerando que bases de recuperação como esta albergam (e vendem) muito do discurso médico e sua vertente dominante, ao passo que excluem todo um circuito de autorias, cuja circulação permanece periférica e, muitas vezes, baseada num pensamento crítico e contra-hegemônico. Afinal, o mercado editorial internacional imputa às produções acadêmicas a clara e atual inscrição de uma commodity ${ }^{34,35}$.

Mas, como já mencionamos, há dominância de trabalhos acadêmicos voltados para a discussão sobre a adoção de hábitos saudáveis pelos indivíduos. E se recorrermos, ainda que ilustrativamente, à produção de conteúdo desenvolvida para despertar na população esses hábitos, veremos que ela é suficientemente afeita à noção de salutarismo. Como exemplo, acessamos o site eletrônico do Ministério da Saúde do Brasil em início de fevereiro de $2019^{36}$. Há uma profusão de enunciados que nos mostram o quão atual a crítica de Crawford é.

Já na página inicial do Ministério da Saúde, encontravam-se duas chamadas de um outro portal denominado Saúde Brasil. Uma delas apresenta ' 7 dicas de alimentação para prevenir a obesidade'; a outra, 'Meditação diminui ansiedade e ajuda no combate à obesidade'. O portal Saúde Brasil é um dos meios eletrônicos oficiais de divulgação do Ministério da Saúde, além das contas em redes sociais como Twitter, Facebook, Instagram e o canal de vídeos na plataforma Youtube. O Saúde Brasil possui quatro eixos de conteúdo, a saber: 'eu quero me alimentar melhor'; 'eu quero me exercitar'; 'eu quero ter peso saudável'; 'eu quero parar de fumar'. A distintiva 'eu quero' revela a centralidade volitiva individual na comunicação em saúde neste caso.

Recorremos à observação das informações que surgem a partir do link ' 7 dicas de alimentação para prevenir a obesidade', que faz parte do componente 'eu quero ter peso saudável'. Ao acessá-la a partir de um laptop, a disposição do site eletrônico é dividida em duas áreas. A primeira, localizada em uma coluna à esquerda, possui um texto explicativo sobre as sete dicas. A segunda área do site, que fica à direita, fornece algumas chamadas que, à primeira vista, se confundem com propagandas veiculadas na internet, comumente associadas ao uso de metadados. Os primeiros links são para uma calculadora de índice de massa corporal e para o 'teste do cigarro', que mediria o grau de dependência da nicotina. Os seguintes, para um vídeo sobre o uso de florais e outro sobre 'metas possíveis para a perda de peso de forma saudável'. As chamadas, seja pela identidade visual, seja pelo modo chamativo com que estão dispostas, aludem a sites de empresas e vendas, sobretudo os demais links para vídeos, igualmente pertencentes ao canal oficial do Ministério da Saúde na plataforma Youtube. Seus títulos mencionam pessoas que tiveram perda de peso de grande monta.

Esses três vídeos têm seu conteúdo apresentado de forma testemunhal, em primeira pessoa, aos moldes de programas religiosos, tendo por título: 'Flávia perdeu 4okg após adotar hábitos mais saudáveis'; 'Lucas perdeu peso e ganhou saúde fazendo atividade física'; 'Priscila escolheu se alimentar de forma saudável e perdeu 79kg' (grifo nosso). O primeiro vídeo mostra como um casal realizou mudanças em sua alimentação, a partir da consulta da mulher com uma nutricionista. No machismo tácito da peça, fica patente a ideia de que a mulher tem a responsabilidade de modificar o marido, pois seu 'maridão também se beneficiou' e emagreceu $17 \mathrm{~kg}$.

ii Já no site Google Acadêmico, as menções ao artigo de Crawford (chamadas no site de 'citações') somam 1.583 resultados. As buscas foram realizadas em janeiro e fevereiro de 2019. 
Em uma habitação notadamente de classe média, a mulher branca mostra, numa cena em que prepara alimentos, como se alimentar de modo saudável não é nada caro, como poderia parecer. Ainda que o preparo e os alimentos sejam inacessíveis a boa parte da população brasileira, pois figuram panelas de aço inox e coloridas, couve-flor, brócolis, pimentões vermelho e amarelo, suco de laranja, seu discurso denota que tudo seria uma questão de planejamento, foco e disciplina. O vídeo mostra fotos de medalhas obtidas pelo casal desportista ao realizar corrida de rua, esporte que, afinal, necessitaria apenas de um par de tênis para sua realização. O processo transformou tanto a vida do casal, que atualmente mudaram de profissão e se tornaram 'coachs em emagrecimento e alimentação saudável'.

O segundo vídeo mostra o testemunho de um jovem designer gráfico branco que abraçou o bike polo, uma modalidade de polo jogada sobre bicicletas no lugar de cavalos, como forma de tentar perder peso. Um dos 'ganhos' apontados foi um novo modo de socialização, uma vez que o jovem conseguiu muitas amizades com este hábito, inclusive se filiando a um clube no estado de São Paulo. Todo o vídeo se passa num cenário de um parque esportivo aparentemente público, arborizado, com quadras muito bem conservadas. Além de, como no vídeo anterior, o personagem ter passado a evitar produtos industrializados, hoje consome aqueles in natura, como legumes e água de coco. Além disso, curte muito mais a vida e faz trilhas com uma mountain bike que, mencionemos, custa em torno de um a três salários mínimos brasileiros. Levando-se em conta os problemas na comercialização e distribuição desigual de alimentos, beber meio litro de água de coco por dia pode custar a uma pessoa cerca de 10 a 15\% do salário mínimo vigente.

No terceiro vídeo, uma bombeira civil branca, moradora de uma rua pavimentada com casas que parecem ser de classe média, conta como perdeu $79 \mathrm{~kg}$. Em seu testemunho, diz que tentou várias dietas, até mudar seus hábitos. Nesta mudança, chegou a fazer uma horta em casa, passou a ir a feiras e hoje foca em 'descascar mais e desembalar menos'. Além disso, trocou o uso do carro por ir a pé (correndo) aos lugares. Este e o conteúdo dos vídeos anteriores evocam a adoção de hábitos saudáveis como modo de encontrar a felicidade, melhorar a saúde, ser ecologicamente correto e até empreender. Poderíamos comentar o quão homogeneizante é a mensagem dos vídeos, pois está abissalmente afastada da dimensão simbólica da relação singular dos sujeitos com a alimentação e a comensalidade - isso se pensarmos apenas no plano individual. Porém, outras questões fundamentais, ligadas à relação entre o consumo de alimentos e o modelo agroindustrial, por exemplo, são igualmente omitidas ${ }^{37}$.

Essas questões deveriam ser quase autoevidentes para qualquer autoridade sanitária, uma vez que são da ordem de intervenções e projetos coletivos. Entre elas, podemos citar: os personagens das histórias estarem relacionados a padrões de classe, raça, gênero e consumo que excluem parte considerável da população do país; os contextos de intensa violência urbana que interferem no cotidiano e no direito de ir e vir de milhões de pessoas das periferias das grandes cidades; a crise de mobilidade, que implica num gasto de tempo expressivo e em desgaste no interior de meios de transporte caros e de baixa qualidade; a falta de habitação adequada e muitos impedimentos ao acesso e à posse de terra; a ação de lobbies dos grandes conglomerados da indústria alimentícia, que trazem obstáculos à elaboração de políticas de vigilância sanitária voltadas para diminuir as concentrações de sal, açúcar e gordura dos alimentos; o fato de haver relação entre o consumo de itens (ultra)processados, baixa renda familiar e precarização do trabalho, sobretudo do trabalho feminino; o modelo de produção de alimentos brasileiro, que tem na tensão entre o favorecimento do agronegócio e a desvalorização de pequenos produtores um desafio à soberania alimentar ${ }^{39-41}$.

Retornando à disposição do site, na coluna à esquerda da tela temos outro elemento, típico do discurso médico corrente que atualiza o salutarismo, que gostaríamos de destacar. Trata-se de um texto com a manchete sobre as sete dicas, cujo conteúdo está organizado de modo análogo ao de outros sites de divulgação científica em saúde. No primeiro trecho, temos o formato de uma entrevista com uma especialista. Antes da palavra da expert, entretanto, há um link de grandes dimensões para um vídeo sobre a relação entre sobrepeso, obesidade e câncer. Depois da primeira manchete que menciona câncer, o texto com a fala 
da especialista é apresentado. Trata-se de uma analista técnica da Coordenação Geral de Alimentação e Nutrição do Ministério da Saúde. As citações de sua fala referem-se à explicação de que a obesidade seria uma doença crônica de múltiplas causas: "O que precisamos entender é que a alimentação vai além das escolhas individuais, sendo influenciada pelo ambiente no qual o indivíduo está inserido" ${ }^{36}$. Ela nomeia esse ambiente de “obesogênico".

Para Daniele Bento ${ }^{39}$, o conceito de "ambiente obesogênico" vem da tentativa de imprimir uma mirada sistêmica ao quadro analítico sobre o aumento da frequência da obesidade no mundo. São consideradas não apenas as questões individuais, mas também a perspectiva política, econômica e sociocultural. O "ambiente obesogênico" seria definido como "circunstâncias ambientais que promovem o consumo de produtos de alta densidade energética, em decorrência, em geral, dos baixos preços dos alimentos, e da facilidade de acesso aos denominados 'fast-food' e caracteriza-se ainda por desencorajar a prática de atividade física" 39 . O que não fica explícito no conteúdo do portal do Ministério da Saúde, e que o trabalho de Bento nos mostra, é que o "ambiente obesogênico" é referido ao chamado "ambiente construído" ${ }^{9}$, que requer a atenção desde o desenho urbano e as condições socioeconômicas até as dinâmicas populacionais de um determinado local.

Retirado de seu contexto original de produção, o conceito de 'ambiente obesogênico' pode ser entendido de um modo que poderíamos chamar de distorcido ou deslocado. A citação indica que obesidade não é algo de base somente individual, e que poderia até ter alguma parte de sua gênese vinda da 'sociedade', o que novamente nos coloca diante de uma mensagem aparentemente paradoxal, tendo em mente os vídeos e o trecho que contém as dicas: "1 - Faça dos alimentos in natura ou minimamente processados e de origem predominantemente vegetal a base da alimentação; 2 - Controle o consumo de alimentos de origem animal; 3 - Utilize óleos, gorduras, sal e açúcar em pequenas quantidades; 4 - Compre mais em feiras livres ou de produtores locais; 5 - Desenvolva habilidades culinárias; 6 - Evite ambientes desfavoráveis; 7. Fique atento à publicidade”36.

Quando tomamos o conjunto das mensagens do eixo "quero ter peso saudável" do portal Saúde Brasil, cujo script preventivo é claramente individualizante, percebemos que o aparente paradoxo pode ter lugar de captura do sentido crítico inicial do 'ambiente obesogênico', de modo a incluir um tom mais coletivo no discurso. Apesar de tudo, um bordão emblemático é entoado pela personagem que teve a maior perda de peso: "A mudança vem primeiro da cabeça. Tem que mudar a cabeça, para mudar o corpo e mudar a vida" 36 . O ideário inerente à esta afirmação é aquele que domina a cena e o conteúdo do site oficial que brevemente observamos. Ao fim e ao cabo, as respostas propostas para os problemas de saúde determinados coletivamente são, inequivocamente, individuais. Entendemos que a mistura de conceitos nesta forma de captura metonímica é parte da atualização, para o neoliberalismo do século XXI, do que Crawford chamou de salutarismo ${ }^{13}$.

\section{O autoritarismo sanitário nosso de cada dia}

$\mathrm{Na}$ seção anterior, apresentamos brevemente mensagens governamentais voltadas para o dito 'emagrecimento saudável'. Seriam elas equivocadas? Não entendemos assim. Chamar de equívoco suscita que, talvez, a forma com que essas mensagens são veiculadas tenha um erro inadvertido, banal, de produção de conteúdo. Ao contrário, compreendemos que a individualização das soluções é uma característica inerente ao salutarismo - no caso, para a obesidade, que é configurada no campo como um problema de saúde.

Esse tipo de encadeamento argumentativo faz parte de uma dimensão importante do salutarismo exposta por Robert Crawford ${ }^{1,33}$ : o efeito de despolitização. Para ele, "como linguagem política, a responsabilidade individual é altamente problemática"1, na medida em que o (auto)controle pode ser entendido como meio de engajamento e, portanto, de eficácia política, funcionando como substitutivo ao "entendimento explicitamente político do problema de saúde"

Isso tem algumas implicações, abordadas por outros autores posteriormente. Em primeiro lugar, juntamente à emergência do salutarismo, caminhou o desenvolvimento de uma moralidade sanitária, em 
que o doente, ou aquele que assume o risco de doença, surge como um perigo moral ${ }^{4}$ à sociedade. A ideia de desvio de conduta ou de falha moral é especialmente oportuna em uma conjuntura em que a racionalidade neoliberal tem desconstruído a ideia de direitos sociais e erigido a metáfora de um mundo-empresa ${ }^{15,34,41}$.

Num mundo-empresa, o que importa são dividendos, obtidos a partir da persecução e da metrificação do desempenho/performance. Aqui há uma chave analítica da atualidade, que carrega consigo um conjunto de valores e uma moral do neoliberalismo. Na saúde, ocorre uma especial complementariedade entre essa lógica gerencial, típica da racionalidade neoliberal, e a ideologia dos riscos sanitários. A essa complementariedade chamamos de "gerencialismo arriscado" ${ }^{13}$. Como consequência, àqueles que não se adequam ou que não atingem as metas de saúde definidas pelo discurso médico, caberia a restrição do que já foi visto como direito social, como o acesso à saúde.

O mecanismo salutarista de despolitização passou por uma captura cínica do que chamamos de participação social. Em um campo, como o da saúde, em que os scripts hiperpreventivos já estão prontos, advindos das boas práticas definidas cientificamente e baseadas em evidências, a ideia de participação pode ser traduzida apenas pela adesão a essas condutas previamente prescritas ${ }^{27,29}$. Uma participação inescapável e, portanto, autoritária.

Obviamente, iniciativas de luta e resistência emergem na arena das práticas e da formulação de políticas, mas não é de hoje que vários movimentos sociais buscam legitimidade científica. Em outras palavras, tentam se justificar no mesmo registro discursivo, e utilizando o mesmo léxico do mecanismo que produz sucessivos apagamentos daquilo que lhes confere existência: a determinação histórica e social dos processos de adoecimento.

Tomando a saúde coletiva brasileira, temos um afastamento da integralidade e um de seus modos de expressão, que seria a demanda socialmente constituída ${ }^{42}$, que pressupunha um diagnóstico epidemiológico ressignificado pelo entendimento local. Mas o que fazer quando 'ganhar saúde' vira 'bater meta'? Mimetizase, no plano individual e no coletivo, o caminho do gerencialismo que, tendo na corporação uma metáfora do mundo, privatiza subjetividades e instituições. Seja ela dada nas práticas cotidianas, do serviço, seja ela pautada claramente nas políticas de saúde. Sobre isso, é fácil lembrar desde as metas de perda de peso, de tomar tantos copos de água por dia até o adicional de salário dos trabalhadores - inclusive os da saúde - por produtividade.

Para Chauí34, a produção de subjetividades neoliberais é uma das faces totalitárias do neoliberalismo, por "recusar a especificidade das diferentes instituições sociais e políticas para torná-las homogêneas", transformando-as em empresas. E, nesse diapasão, os mecanismos de resistência coletiva enfrentam maiores dificuldades. Ora, se saúde é constituída como um supervalor, se devemos proteger nosso corpo e atualmente monitorá-lo ao extremo, assumindo a responsabilidade por desfechos desfavoráveis que pretensamente advêm de nossas más escolhas como indivíduos cônscios e com toda a capacidade de correr atrás de nossos sonhos e superar as adversidades, qual o lugar da luta pelo bem coletivo?

Esse ideário não se resume à emanações discursivas de grupos leigos, mas encontra-se embasado, como estivera no início do século XX, na produção acadêmica, inclusive em periódicos da área biomédica bem classificados nos estratos da avaliação Qualis da Capes, mesmo no campo da saúde coletiva. Como expusemos anteriormente em nossos ensaios sobre o cinismo em saúde ${ }^{13}$, há sugestões como a de colocar substâncias estimulantes, como o medicamento Ritalina ${ }^{\circ}$ (nome comercial do metilfenidato produzido no Brasil pelo laboratório Novartis) em reservatórios de água de países e/ou populações pobres. Isso seria justificado, segundo a vertente teórica de alguns neuroeticistas, chamada de 'neuroaprimoramento moral farmacológico', pela 'falência' dos sistemas educacionais no que diz respeito a orientar devidamente as pessoas (pobres) a terem escolhas mais saudáveis.

O mesmo acontece com a proposta de casais (heterossexuais) utilizarem amplamente o hormônio oxitocina como forma de evitar as atuais altas taxas de divórcio, o que supostamente trariam prejuízos ao desenvolvimento das crianças ${ }^{13}$. Obviamente, a verve científica totalitária e eugênica nunca foi deixada 
de lado e, atualmente, coloca-se como uma tendência a disputar as narrativas em torno da produção acadêmica que compõe o discurso médico e, consequentemente, as políticas e práticas sanitárias. Não é de se estranhar, portanto, que outras capturas falaciosas, tais como a de 'ideologia de gênero' - que suprime a problematização das desigualdades de gênero -, ou a proibição de alguns métodos contraceptivos, estejam na pauta do debate político nacional.

Na conjuntura em que o Brasil está inserido, de novas (contra)reformas de Estado, pautadas pela financeirização do capital, pelo aumento da concentração de renda e que tem como objetivo a ampliação das políticas de ajuste fiscal ${ }^{34}$, a perspectiva doutrinária salutarista se adequa perfeitamente ao presente momento do neoliberalismo. Apesar dessa conjuntura apontar para prováveis danos à saúde ${ }^{43}$, podemos perguntar: afinal, em um mundo hiperindividualizado, qual o sentido político do Sistema Único de Saúde, sendo ele um projeto coletivo, que implica na ideia de um sistema de saúde público, gratuito, universal e, fundamentalmente, que tem como dimensão-chave a integralidade das ações?

Tendo em vista este momento histórico, ler os textos de Crawford ajuda a compreender, em certa medida, o campo da saúde e o da saúde coletiva, como seu lugar de resistência. Por outro lado, seus textos auxiliam, também, a leitura crítica desses campos e do quanto eles produzem e reproduzem as ideias autoritárias que encerram o salutarismo.

\section{Referências}

1. Crawford R. Salutarismo e medicalização da vida cotidiana. Reciis. 2019;13(1):100-121. [citado em 2019 jan. 8] Disponível em: https://www.reciis.icict.fiocruz.br/index.php/reciis

2. University of Washington Tacoma, Faculty \& Staff Directory. Robert Crawford, Ph.D. [Internet]. [citado em 2019 jan. 19]. Disponível em: http://directory.tacoma.uw.edu/employee/crawford

3. University of Washington Tacoma, News \& Information. Once a teacher... [Internet]. [citado em 2019 fev. 06]. Disponível em: https://www.tacoma.uw.edu/news/article/once-teacher

4. Lupton D. Risk as moral danger: the social and political functions of risk discourse in public health. Int J Health Serv. 1993;23(3):425-35.

5. Stark E. The Epidemic as a Social Event. Int. J. Health Serv. 1977;7(4):681-705. doi: https://doi. org/10.2190/16AY-E2GC-DFLD-51X2

6. Crawford R. You are dangerous to your health: the ideology and politics of victim blaming. Int J Health Serv. 1977; 7(4):663-80. doi: https://doi.org/10.2190/YU77-T7B1-EN9X-GOPN

7. Crawford R. Healthism and the medicalization of everyday life. Int J Health Serv. 1980;10(3):365-88. doi: https://doi.org/10.2190/3H2H-3XJN-3KAY-G9NY

8. Catálogo Coletivo Nacional de Publicações Seriadas. Consulta ao CCN. Disponível em: http://ccn.ibict.br/ busca.jsf [citado em 2019 jan. 19].

9. Sage Publishing. Welcome to Sage. [Internet]. [citado em 2019 jan. 19]. Disponível em: https:// us.sagepub.com/en-us/sam

10. Castiel LD, Sanz-Valero J, Vasconcellos-Silva PR. Das loucuras da razão ao sexo dos anjos: biopolítica, hiperprevenção, produtividade científica. Rio de Janeiro: Fiocruz; 2011.

11. Zola I. Healthism and disabling medicalization. In: Illich I, Zola IK, McKnight J, Caplan J, Shaiken H, organizadores. Disabling professions. London: Marions Boyars Publishers; 1977. p. 41-68.

12. Illich I. Medical Nemesis: the expropriation of health. New York: Pantheon Books; 1976.

13. Castiel LD, Xavier, C, Moraes DR. À procura de um mundo melhor: apontamentos sobre o cinismo em saúde. Rio de Janeiro: Fiocruz; 2016.

14. Moraes DR; Castiel LD, Ribeiro APPGA. "Não" para jovens bombados, "sim" para velhos empinados: o discurso sobre anabolizantes e saúde em artigos da área biomédica. Cad. Saúde Pública.

2015;31(6):1131-40. doi: http://dx.doi.org/10.1590/0102-311X00068914. 
15. Dardot P, Laval C. A nova razão do mundo: ensaio sobre a sociedade neoliberal. São Paulo: Boitempo Editorial; 2016.

16. Guilam MCR. O conceito de risco: sua utilização pela epidemiologia, engenharia e ciências sociais [Internet]. 2004 [citado em 2019 fev. 02]; Disponível em: https://fenix.tecnico.ulisboa.pt/ downloadFile/3779571681924/conceito\%20de\%20risco\%20-\%20sua\%20utilizacao.pdf

17. Weisz G, Olszynko-Gryn J. The theory of epidemiologic transition: the origins of a citation classic. J Hist Med Allied Sci.. 2010;65(3):287-326. doi: https://doi.org/10.1093/jhmas/jrp058

18. Sabroza PC. Concepções sobre saúde e doença [Internet]. Rio de Janeiro: Escola Nacional de Saúde Pública Sergio Arouca; 2006 [citado 2019 jan. 12] . Disponível em: http://www.abrasco.org.br/UserFiles/ File/13\%20CNS/SABROZA\%20P\%20ConcepcoesSaudeDoenca.pdf

19. Breilh J. Epidemiologia crítica: ciência emancipadora e interculturalidade. Rio de Janeiro: Fiocruz; 2006.

20. Iriart C, Waitzkin $\mathrm{H}$, Breilh J, Estrada A, Merhy EE. Medicina social latinoamericana: aportes y desafios. Rev Panam Salud Publica; 2002;12(2):128-36.

21. Silva LS, Cotta RMM; Rosa COB. Estratégias de promoção da saúde e prevenção primária para enfrentamento das doenças crônicas: revisão sistemática. Rev Panam Salud Publica; 2013;34(5):343-50.

22. Moraes DR. Entre tiro, porrada e bomba: esteroides anabolizantes androgênicos, gerencialismo arriscado e os discursos médicos moralizantes [tese]. Rio de Janeiro: Fundação Oswaldo Cruz, Escola Nacional de Saúde Pública; 2016. 165 p.

23. Cardoso JM, Rocha RL. Interfaces e desafios comunicacionais do Sistema Único de Saúde. Ciênc. saúde coletiva. 2018; 23(6):1871-80. doi: http://dx.doi.org/10.1590/1413-81232018236.01312018

24. Stotz EN, Araujo JWG. Promoção da saúde e cultura política: a reconstrução do consenso. Saúde soc. 2004;13(2):5-19. doi: http://dx.doi.org/10.1590/S0104-12902004000200002

25. Lefevre F, Lefevre AMC. Saúde como negação da negação: uma perspectiva dialética. Physis. 2007;17(1):15-28. doi: http://dx.doi.org/10.1590/S0103-73312007000100002

26. Ferreira MS. Agite antes de usar... A promoção da saúde em programas brasileiros de promoção da atividade física: o caso do Agita São Paulo [tese]. Rio de Janeiro: Fundação Oswaldo Cruz, Escola Nacional de Saúde Pública; 2008. 252 p.

27. Lupton D, Petersen A. The imperative of health: public health and the regulated body. London: Sage; 1995.

28. Petersen A, Lupton D. The new public health: health and self in the age of risk. London: Sage; 1996.

29. Ayo N. Understanding health promotion in a neoliberal climate and the making of health conscious citizens. Critical Public Health. 2012;22(1):99-105. doi: https://doi.org/10.1080/09581596.2010.520692

30. Porto MFS, Cunha MB, Pivetta F, Zancan L, Freitas JD. Comunidades ampliadas de pesquisa ação como dispositivos para uma promoção emancipatória da saúde: bases conceituais e metodológicas. Ciênc. saúde coletiva. 2016;21(6):1747-56. doi: http://dx.doi.org/10.1590/1413-81232015216.25802015

31. Klein A. La fin de la biopolitique? Les transformations contemporaines de la santé publique [Internet]. HistoireEngagée.ca; 2017. [citado em 2019 jan. 12] Disponível em: http://histoireengagee.ca/la-fin-dela-biopolitique-les-transformations-contemporaines-de-la-sante-publique/

32. Foucault M. Crise da medicina ou crise da antimedicina. São Paulo: Verve. 2010;18. p. 167-94.

33. Crawford R. Health as a meaningful practice. Health (London). 2003;10(4):401-20. doi: https://doi. org/10.1177/1363459306067310

34. Chauí M. Conferência a covardia é a mãe da crueldade. Revista do Nesef. 2018;7(2):146-57.

35. Oliveira MB. Ciência: força produtiva ou mercadoria? Crítica Marxista. 2005; 21(1):77-96.

36. Brasil, Ministério da Saúde. Eu quero ter peso saudável: 7 dicas de alimentação para prevenir a obesidade. [Internet]. 2018 out. [citado em 2019 fev. 05 ]. Disponível em: https://saudebrasilportal. com.br/ter-peso-saudavel/7-dicas-de-alimentacao-para-prevenir-a-obesidade

37. Triches RM, Gerhardht TE, Schneider S. Políticas alimentares: interações entre saúde, consumo e produção de alimentos. Interações. 2014;15(1):109-20. 
38. Winnie LWY. O campo científico da soberania e segurança alimentar e nutricional no Brasil: grupos e linhas de pesquisa de 2000 a 2016. [dissertação] Piracicaba: Universidade de São Paulo; 2017. 141 p.

39. Bento DFMCR. A importância do ambiente obesogênico na população de alta vulnerabilidade social em Campinas/SP [tese]. Campinas: Universidade Estadual de Campinas; 2017. 159 p.

40. Miranda AC, Moreira JC, Carvalho R, Peres F. Neoliberalismo, uso de agrotóxicos e a crise da soberania alimentar no Brasil. Ci. Saúde Coletiva. 2007;12(1):7-14. doi: http://dx.doi.org/10.1590/S141381232007000100002

41. Gaulejac V. Gestão como doença social: ideologia, poder gerencialista e fragmentação social. Aparecida: Ideias \& Letras; 2007.

42. Camargo Jr KR. Das necessidades em saúde à demanda socialmente constituída. In: Construção social da demanda: direito à saúde, trabalho em equipe, participação em espaços públicos, Pinheiro R, Araujo RM, organizadores. Rio de Janeiro: IMS/Uerj-Cepesc-Abrasco, 2005; p. 91-101.

43. Malta DC, Duncan BB, Barros MBA, Katikireddi SV, Souza FM, Silva AG et al. Medidas de austeridade fiscal comprometem metas de controle de doenças não transmissíveis no Brasil. Ci. Saúde Coletiva. 2018;23(10):3115-22. doi: http://dx.doi.org/10.1590/1413-812320182310.25222018 